\title{
AVALIAÇÃO DO CALIFORNIA MASTITIS TEST E DA CONTAGEM DE CÉLULAS SOMÁTICAS PARA O DIAGNÓSTICO DA MASTITE SUBCLÍNICA CAPRINA ${ }^{1}$
}

Francisco Selmo Fernandes Alves ${ }^{2}$, Raymundo Rizaldo Pinheiro ${ }^{3}$, Lauana Borges Santiago ${ }^{4}$, Vanderlan Warlington Souza dos Santos ${ }^{5}$, Geisa Isilda Ferreira Esteves ${ }^{6}$, Carlos José de Moura ${ }^{7}$, David Tenório de Barros $^{7}$

\author{
${ }^{1}$ Estudo financiado pela Embrapa Caprinos e Fundação Cearense de Apoio ao Desenvolvimento Científico e Tecnológico \\ (FUNCAP); \\ ${ }^{2}$ Médico Veterinário - Pesquisador da Embrapa Caprinos. e-mail: selmo@cnpc.embrapa.br (autor para correspondência); \\ ${ }^{3}$ Médico Veterinário - Pesquisador da Embrapa Caprinos e Professor da UVA; \\ ${ }^{4}$ Mestranda do Programa de Pós-Graduação em Zootecnia - UVA/Embrapa Caprinos. Bolsista FUNCAP; \\ ${ }^{5}$ Graduando em Zootecnia - UVA. Bolsista FUNCAP; \\ ${ }^{6}$ Graduanda em Medicina Veterinária - UGF; \\ ${ }^{7}$ Graduando em Medicina Veterinária - UFRPE.
}

Resumo: Vários estudos têm confirmado diferenças fisiológicas entre a glândula mamária caprina e a bovina, demonstrando que devem ser realizadas adaptações para caprinos, determinando escores que melhor reflitam o verdadeiro estado sanitário da glândula mamária nesta espécie. O objetivo deste estudo foi correlacionar os resultados do Califórnia Mastitis Test (CMT), da contagem de células somáticas (CCS) e do exame bacteriológico do leite de caprinos e comparar com os padrões existentes na literatura. Foram utilizadas 23 fêmeas da raça Saanen pertencentes a Embrapa Caprinos e realizados exame clínico dos animais e teste da caneca telada, sendo que nenhum animal apresentava sintomas de mastite clínica. Posteriormente realizou-se o CMT, a coleta de leite para a contagem de células somáticas e exame microbiológico. Para a análise estatística foi utilizado o programa Assistat 7.5. Não foi observada diferença estatística significativa entre os escores $3+$ e $2+$ ou entre os escores $1+$, traços e 0 do CMT, quando correlacionado com o exame microbiológico. A reação $3+$ foi estatisticamente diferente $(\mathrm{p}<0,01)$ das reações $1+$, traços e 0 . Considerando o valor de $1120 \times 10^{3}$ céls $/ \mathrm{mL}$ como o limite máximo de células no leite caprino, foi demonstrada diferença altamente significativa $(\mathrm{p}<0,001)$ entre as amostras microbiologicamente positivas e negativas. Quanto à correlação entre a CCS e o CMT, foi constatada diferença significativa $(\mathrm{p}<0,05)$ somente entre os escores 0 e $3+$ do CMT.

Palavras-chave: caprinos, glândula mamária, exame microbiológico, leite, testes

\section{Evaluation of California Mastitis Test and Somatic Cells Count for the diagnosis of subclinical mastitis in goats}

Abstract: The physiological differences existed between mammary gland of bovine and goat have been confirmed by several researchers nowadays, proving the utilization of indirect testes for diagnosis of mastitis in goats deserves a different interpretation. The aim of this study was to correlate the California Mastitis Test (CMT) scores, the Somatic Cells Count (SCC) and the microbiological exam, comparing with the existent patterns of literature. 23 Saanen goats of Brazilian Agriculture Research Enterprise Embrapa were used, clinical exam accomplished and a wired cup test realized which showed none of the animal with symptom of mastitis. The CMT was realized and samples were collected for SCC and microbiological exam. Statistical analysis was made by Assistat program 7.5. There was no statistical difference between $3+$ and $2+$ scores or between $1+$, line and 0 of CMT, when compared with microbiological exam. Reaction $3+$ was statistically different $(\mathrm{p}<0,01)$ of the reactions $1+$, lines and 0 . Considering the value of $1,120 \times 10^{3}$ céls $/ \mathrm{mL}$ as the maximum limit of cells accepted in the goat milk, difference was demonstrated highly significant $(\mathrm{p}<0,001)$ among the samples microbiological positive and negative. In relationship to the correlation between CCS and CMT, significant difference was verified $(\mathrm{p}<0,05)$ only among the scores 0 and $3+$ of CMT.

Keywords: goats, mammary gland, microbiological exam, milk, tests

\section{Introdução}

A mastite representa um fator limitante para a produção de leite e um problema em rebanhos no mundo. As perdas econômicas causadas por esta enfermidade estão relacionadas a custos com descarte de leite, tratamento dos animais, assistência veterinária e diminuição da quantidade e qualidade de leite produzida. Diferentemente do que ocorre na mastite subclínica, o diagnóstico da mastite clínica é bastante simples, sendo realizado através da observação dos sinais clínicos da enfermidade apresentados pelos animais. Um método bastante eficaz para detectar a mastite subclínica em um rebanho consiste na 
realização de exame bacteriológico do leite. Entretanto, algumas limitações como o custo do teste e a deficiência quanto à existência de uma rede de laboratórios veterinários estruturada para dar suporte a técnicos e produtores dificultam a utilização rotineira deste teste (Silva et al., 1996). Os métodos auxiliares mais difundidos na bovinocultura leiteira são baseados no aumento do conteúdo celular da glândula mamária, como a contagem de células somáticas (CCS) e o California Mastitis Test (CMT). A grande quantidade de células epiteliais e partículas anucleadas presentes no leite caprino interfere, significativamente, nos testes de rotina utilizados para detectar a forma subclínica da doença. Vários estudos têm indicado e confirmado diferenças fisiológicas e microbiológicas entre a glândula mamária caprina e a bovina, demonstrando que devem ser realizadas adaptações para os caprinos, determinando escores que melhor reflitam o verdadeiro estado sanitário da glândula mamária nesta espécie (Silva et al., 2001). Assim, o objetivo deste estudo foi correlacionar os resultados do California Mastitis Test, da contagem de células somáticas e do exame microbiológico do leite de caprinos, comparar os dados obtidos com os padrões descritos na literatura para esta espécie e avaliar a utilização destes testes para o diagnóstico da mastite subclínica em cabras.

\section{Material e Métodos}

O presente estudo foi desenvolvido no Centro Nacional de Pesquisa em Caprinos da Embrapa, localizado no município de Sobral-CE, na região semi-árida do sertão cearense, à $3{ }^{\circ} 42^{\prime}$ de latitude Sul e $40^{\circ} 21^{\prime}$ de longitude Oeste, numa altitude de $83 \mathrm{~m}$. Foram utilizadas 23 fêmeas caprinas da raça Saanen, pertencentes ao Setor Leiteiro do CNPC. Inicialmente foi realizado o exame clínico dos animais e teste da caneca telada com os jatos iniciais da ordenha, sendo que nenhum animal apresentava sintomas de mastite clínica. Posteriormente realizou-se o California Mastitis Test e a coleta de leite para a contagem de células somáticas (CCS), em frascos de $50 \mathrm{~mL}$ contendo conservante Bronopol ${ }^{\circledR}$, realizada pelo método de citometria de fluxo em equipamentos Bentley ${ }^{\circledR}$. Por último, após higienização do teto com álcool $70 \%$ e iodo a $10 \%$, foi realizada a coleta de leite para exame microbiológico, em frascos de $10 \mathrm{~mL}$ estéreis, seguindo metodologia descrita por Carter et al. (1986). Foram atribuídos os escores 0, traços, 1+, 2+ e 3+, respectivamente para a ausência de reação, reação leve com tendência a desaparecer, presença de grumos sem gelificação, imediata formação de gel e ocorrência de gelificação e aderência. Todos os testes foram realizados individualmente por teto, para comparação dos dados. As amostras de leite foram coletadas na ordenha da tarde e enviadas imediatamente aos laboratórios em caixa isotérmica contendo gelo reciclável. A CCS foi realizada no Laboratório de Qualidade do Leite da Embrapa Gado de Leite e o exame microbiológico, no Laboratório de Bacteriologia da Embrapa Caprinos. Para a análise estatística dos dados foi utilizado o Programa Assistat 7.5 (Silva \& Azevedo, 2006).

\section{Resultados e Discussão}

Ao correlacionar os resultados do CMT com o exame microbiológico das amostras de leite, não foi observada diferença estatística significativa entre os escores $3+$ e $2+$ ou entre os escores $1+$, traços e 0 do CMT. Somente a reação $3+$ foi estatisticamente diferente $(\mathrm{p}<0,01)$ das reações $1+$, traços e 0 obtidas no teste. Em relação à comparação realizada entre a CCS e o teste microbiológico, ao considerar o valor de 1120 × $10^{3}$ céls/mL como o limite máximo de células fisiologicamente admissível no leite caprino (Silva et al., 2001), foi demonstrada diferença estatística altamente significativa $(\mathrm{p}<0,001)$ entre as amostras microbiologicamente positivas e negativas. E, finalmente, quanto à correlação existente entre a CCS e o CMT, foi constatada diferença estatística significativa $(\mathrm{p}<0,05)$ somente entre os escores 0 e $3+$ do CMT, como demonstra a figura 01 . Na associação destes dois testes, foram obtidas as médias de 161,$75 ; 356,75 ; 298,33 ; 586,36$ e $895,33 \times 10^{3}$ céls/mL para as reações 0 , traços, 1+, 2+ e 3+ do CMT, respectivamente. Tais valores foram bastante inferiores aos descritos por Rota et al. (1994). Esta discrepância pode ter ocorrido pela subjetividade do CMT, havendo uma superestimação, de maneira geral, das reações observadas no teste. Após a análise dos resultados obtidos neste estudo, fica clara a idéia de que os resultados obtidos pelo CMT devem ser utilizados com bastante cuidado, já que reações positivas não, necessariamente, indicam infecção da glândula mamária. Da mesma maneira, a utilização da CCS para o controle de mastite subclínica de um rebanho caprino deve ser cautelosa, apesar de este estudo ter demonstrado boa correlação com os resultados do exame microbiológico das amostras de leite. Além da peculiaridade da espécie caprina quanto à maior presença de células e corpúsculos citoplasmáticos no leite, em relação aos bovinos, a fase de lactação e a produção de leite dos animais também são citadas como fatores que podem exercer influência nos valores de celularidade do leite. Cabras no final da lactação e com baixa produção leiteira tendem a apresentar maior teor de células somáticas e, conseqüentemente, maior será a probabilidade de obtenção de resultados falso-positivos, seja pelo CMT ou pela CCS (Hinckley, 1990). 


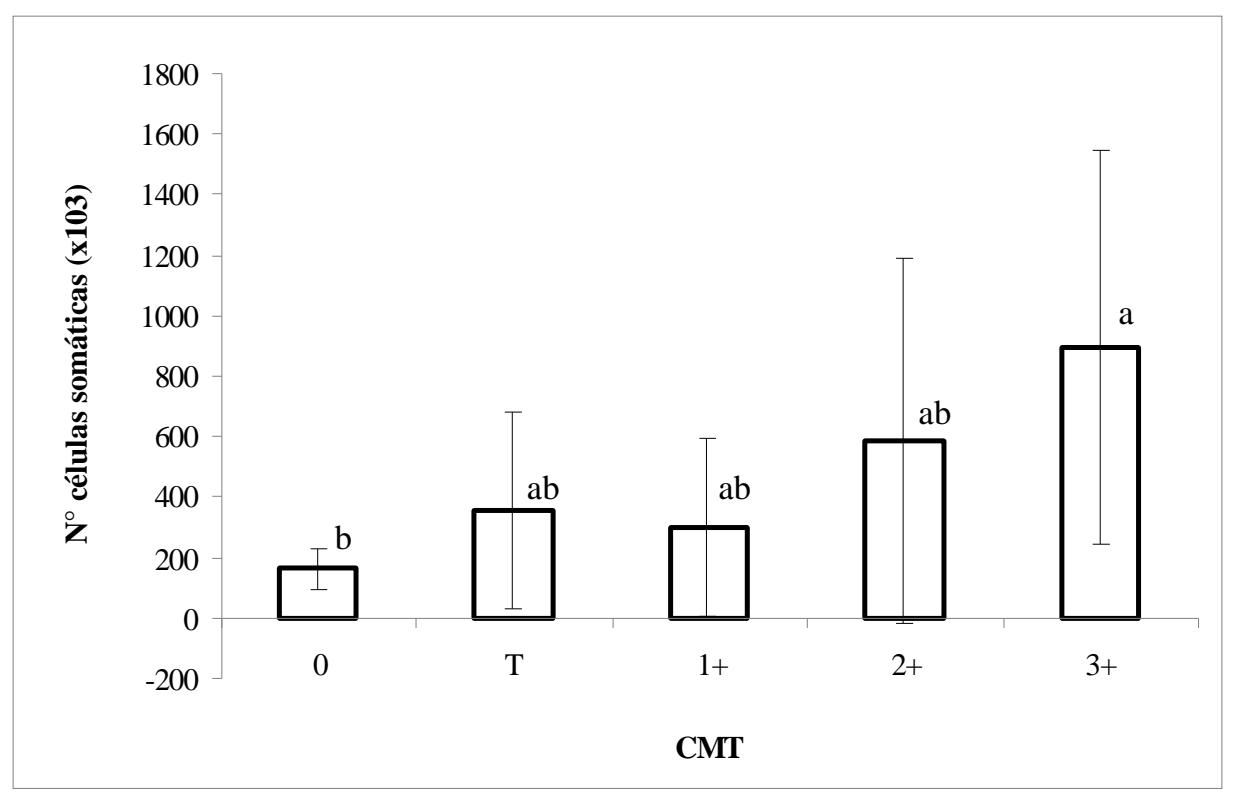

Figura 01. Resultados da contagem de células somáticas relacionados com os escores obtidos no California Mastitis Test; letras minúsculas diferentes representam diferença estatística significativa $(\mathrm{p}<0,05)$.

\section{Conclusões}

O CMT e a CCS são úteis no diagnóstico da mastite subclínica caprina, desde que os resultados positivos sejam interpretados com bastante cautela. A fisiologia da glândula mamária dos caprinos, a produção leiteira, a fase e o número de lactações dos animais devem ser considerados na avaliação dos resultados. Para obtenção de um diagnóstico mais seguro da enfermidade, recomenda-se a associação dos testes indiretos com o exame microbiológico do leite.

\section{Agradecimentos}

À Embrapa Caprinos por ter cedido o espaço físico e os animais, além do apoio financeiro junto a Fundação Cearense de Apoio ao Desenvolvimento Científico e Tecnológico (FUNCAP).

\section{Literatura citada}

CARTER, G. R.; CLAUS, W.; RIKIHISA, Y. Essencials of veterinary bacteriology and mycology. 3.ed. Philadelphia: Lea \& Febiger, 1986. 261 p.

HINCKLEY, L. S. Revision of the somatic cell count standart for goat milk. Dairy, Food and Environmental Sanitation, v. 10, n. 9, p. 548-549, 1990.

ROTA, A. M.; ROJAS, A.; MARTÍN, L.; RODRÍGUEZ, P.; TOVAR, J. J. Uso de la prueba de California para la detección de mamitis en el ganado caprino. Avances en Alimentacion y Mejora Animal, v. 2, n. 34, p. 67-69, 1994.

SILVA, E. R.; ARAÚJO, A. M.; ALVES, F. S. F.; PINHEIRO, R. R.; SAUKAS, T. N. Associação entre o California Mastitis Test e a Contagem de Células Somáticas na avaliação da saúde da glândula mamária caprina. Brazilian Journal of Veterinary Research and Animal Science, v. 38, n. 1, 2001.

SILVA, E. R.; SAUKAS, T. N.; ALVES, F. S. F.; PINHEIRO, R. R. Contagem de células somáticas e California Mastitis Test no diagnóstico da mastite subclínica caprina. Sobral: Embrapa CNPC, 1996. 26p. (Embrapa-CNPC. Documentos, 30).

SILVA, F. A. S.; AZEVEDO, C. A. V. A new version of the Assistat-Computers in Agriculture, 4, Orlando-FL-USA: Anais... Orlando: American Society of Agricultural Engineers, 2006. p. 393-396. 